\title{
Research on the Motivation and Tendency of Enterprise Performance Evaluation in Information Economy
}

\author{
Hong JI \\ Jiangxi Normal University Science and Technology College \\ Nanchang, China \\ jxsdjh@vip.sina.com
}

\author{
Pei-wen ZHANG \\ Jiangxi Normal University Business College \\ Nanchang, China
}

\begin{abstract}
The information economy era brings the enterprise business environment, the rapid change of customer demand and competition, and puts forward new challenges to enterprise management. This paper analyzes the mechanism of enterprise performance management from the perspective of enterprise informatization to the enterprise competitiveness mechanism, puts forward the unique competitive advantage of enterprise information, that is, the knowledge advantage is gradually transformed into the backbone of the enterprise's core competition, and the loopholes in the traditional performance evaluation under the uncertain competitive environment, The core evaluation contents of strategic performance evaluation system are discussed, focusing on strategic management, dynamic real-time process reflection, non-financial indicators, knowledge and intellectual capital, and the requirements of stakeholders.
\end{abstract}

Keywords-performance evaluation; strategic management; non - financial indicators

\section{INTRODUCTION}

The information age brought to the enterprise brought about by the technical explosion, equal resources, economic globalization and integration, consumers increasingly mature and complex, new social values and other challenges and expectations, revealing the business to face the new competitive environment Adaptability strategy, rapid and flexible implementation, continuous innovation, Mass customization and adaptation of culture and other potential advantages of competitiveness. Now the rapid development of information technology, competitive environment, organizational structure, management mode and customer needs of enterprises are undergoing profound changes. The original performance evaluation system has obviously failed to meet the needs of enterprise management and competitive environment in the information age, the performance evaluation system, which is an important part of the management and control system, should also be adaptively adjusted.

\section{The CHANGE OF ENTERPRISE MANAGEMENT IN INFORMATION ECONOMY}

As a result of the extensive application of information technology, improve and strengthen the enterprise's products, information, personnel and capital flow integration management, the enterprise's internal business thinking and management model had a fundamental impact. Enterprise management and information technology integration management so that enterprise competition strategy management innovation, enterprise competitiveness continues to improve. Information resources, systems and technology are no longer just to support the corporate strategy, but also help to determine the corporate strategy, information strategy has become an important part of the company's strategy; competitive advantage is no longer limited to the cost of gathering the three major forms of enterprise information unique of the competitive advantage - the advantages of knowledge has gradually become a competitive advantage of competitive advantage, enterprise information has become an irresistible inevitable trend.

\section{A. To effectively reduce costs and expand the scope of competition}

The application of information technology involves the economic activities of the whole enterprise, which objectively connects every aspect of the enterprise value chain cost, the improvement and the close cost structure. The decline of information technology costs, its essence is to improve the efficiency of the development and utilization of information resources, information resources to be absorbed and used and expand the scope of the enterprise can be used to share the cost of information resources management costs, and integration of management scale power Management results, improve the way of competition for enterprises to provide a new competitive space, so that many companies use the "virtual enterprise" this strategic alliance to obtain a competitive advantage [1]. In the complementary advantages on the basis of cooperation, and vigorously expand the scope of enterprise resource optimization configuration, through mutual learning alliance, so that a single enterprise tackling difficulties, thereby expanding the business and reduce risk. Competition is to improve the creativity and enthusiasm of enterprises to achieve the minimum cost of flexible external demand, so that the company level changes with the times, to promote the optimal allocation of resources to improve the core competitiveness of enterprises. 


\section{B. To improve the competitiveness of products to promote technological innovation}

With the development of the network, so that global information access to unprecedented cross-regional, cross-border movement, information flow to create unimpeded business opportunities, especially e-commerce business management in a wide range of applications to narrow the distance between goods and consumers, so that enterprises get new Technology, new ideas, to promote enterprises to improve efficiency More accurate understanding of the market and consumers, so that enterprises can quickly meet the needs of consumers to make decision-making enterprises, through real-time changes and adjust the strategic program to form a unique competitive advantage. Modern market information resources to form a variety of high-tech enterprise information technology, to achieve the e-business thinking, design, production, sales and management of a high degree of integration, so in production and operation on the modern, efficient, virtual, and enhance the flexibility of production Sex and adaptability, making it more accurate, intelligent and efficient.

\section{Improve the overall function of enterprise information technology management}

With the development of the network and the application of various decision tools, the seamless integration of information technology and information resources, so that enterprises in the use, promotion, integration of information resources more efficient, fast, extensive management process to form a complete system , To ensure that information, decision-making and development of a high degree of focus on the implementation of accurate, help enterprises to manage decision-makers on the perception of information, program value assessment capabilities, decision-makers wisdom to minimize decision-making process of uncertainty, Subjective, to enhance the rationality of decision-making, scientific and rapid response to improve the efficiency and efficiency of decision-making. Enterprise information is not only the computer hardware conditions, and managers of the decision-making and ideological integration is also an important aspect. In other words, in the process of information technology, by updating the traditional enterprise management concept, the effective use of information technology, the establishment of good management practices and management processes for enterprise management to lay a solid foundation for the implementation of scientific management, thereby strengthening the overall management level.

\section{Promote business process reengineering, and promote organizational structure optimization}

The traditional organizational structure of the existence of multi-level, multi-level, institutional bloated, horizontal communication difficulties, information transmission distortion, lack of vitality, slow response to external changes and other defects. After the 1990s, due to the intensification of market competition, diversification of customer demand, individuality and social environment changes, so that enterprises are facing increasingly complex and volatile market environment, the traditional enterprise management model can not adapt. The rapid development of information technology, fundamentally changed the organization to collect, process, use the information, resulting in a huge change in organizational form, to promote the business process reengineering (BPR) and organizational structure of the reconstruction. The original tower structure for the sophisticated, agile, innovative spirit of the flat dynamic network structure replaced. In this framework, on the one hand, the computer system will replace a large number of management and control functions of a large number of departments to make communication decisions and business execution level more accurate, the impact of management is weakened, Impact; on the other hand, the work group will become the main business management model, management from control to participation, grant the group a high degree of freedom. Work grouping through the layers of information to coordinate the various departments within the business, to achieve dynamic management between the business sectors.

\section{LIMITATIONS OF ENTERPRISE'S TRADITIONAL} PERFORMANCE EVALUATION UNDER INFORMATION ECONOMY

Today, competition, technology, management trends and the rise of the information economy, forcing companies to successfully develop strategies and better than competitors in the implementation of corporate strategy in order to enterprises and customers continue to create value. The new competitive environment puts forward new requirements for the performance evaluation of the enterprise [2]. The traditional performance evaluation system which is oriented to the enterprise within ten years seems to be no longer adaptable, so it can not fully reflect the resources and strength of the enterprise.

\section{A. Too much emphasis on obtaining and maintaining short-term financial results}

Cannot stand at the height of the strategy to fully reveal the key performance reasons for performance improvement, the lack of predictability of future performance, the company is reluctant to reduce the current profitability of capital investment, weakening the pursuit of long-term strategic objectives, Managers and the short-term speculation behavior, resulting in short-term performance of enterprises in the long-term investment in the long-term value creation, such as conducive to the growth of enterprises invisible knowledge, intellectual assets, too little investment.

\section{B. Excessive focus on direct valuation of financial indicators, ignoring non-financial indicators}

Due to the uncertainties of the environment, the ever-changing market and the complexity of the business activities, the performance evaluation of the enterprise is not measurable, and the uncertain factors are more and more. However, when the competitive environment needs more and more enterprises to pay attention to and make business decisions, Rate, customer satisfaction, innovation, quality and service, employee satisfaction, staff training and other non-financial indicators should play a greater role in performance evaluation. Especially in the intangible assets, especially intellectual capital, the simple financial indicators can not reflect the whole picture of business, cannot grasp the 
key changes in the enterprise, can not find the key factors to create value.

\section{Performance evaluation and corporate valuation of the uncoordinated}

Because the traditional performance evaluation adopts the method of accounting income and accounting yield, it is considered that the accounting profit deducted from the debt cost is the equity capital appreciation, and ignores the opportunity cost of equity capital. From the perspective of business owners, performance evaluation and corporate valuation are closely linked. In the capital market under the conditions of efficiency, the value of the enterprise to become the core of evaluation, that is, the evaluation system indicators are ultimately related to the value. The value is related to the following three aspects: First, the current profitability (measured by monetary indicators); Second, the sustainability of profitability (health indicators); Third, the growth potential of profitability (value drivers, etc.) [3]. Value is in essence based on historical and current performance to anticipate the future, rather than the importance of financial indicators is the profitability of the sustainability and growth potential to give an estimated basis, and gives the current profitability of the side of the verification.

\section{Cannot meet the management innovation needs of the information}

In a competitive environment, management innovation requires information about all aspects of the business, including not only financial and operational results, but also non-financial, information related to the business process. For example, many companies are adopting the Total Quality Management (TQM) program, which requires timely and detailed process information to identify where operational deficiencies are located to monitor the consequences of subsequent improvement activities that can not be made from general accounting Data obtained.

\section{E. Reflect the business past and present business situation}

Because the current accounting system is based on historical cost and accrual basis, the financial basis data is often difficult to reflect the true value of the enterprise, and it is easy to produce profit manipulation problem, so the financial indicators are easy to distort, based on this Performance evaluation is often unfair and can not objectively evaluate operator performance. At the same time due to focus on the static evaluation afterwards, can not be timely business process dynamic evaluation, making the enterprise can not find the deviation of the business process, and take timely and effective remedial measures.

\section{DEVELOPMENT TREND OF ENTERPRISE PERFORMANCE EVALUATION UNDER INFORMATION ECONOMY}

The traditional performance evaluation system has not been able to adapt to the changes of the environment and the corresponding enterprise management reform because of its inherent defects, which are unprecedented in the enterprise strategy, organization form, financial management, value estimation and employee incentive mechanism brought by the new economic environment. The whole enterprise performance evaluation theory foundation and method system in the complex and changeable environment also faces severe challenge.

\section{A. Performance evaluation into the whole process of strategic management}

In the enterprise management, performance evaluation system has a guiding role. Traditional evaluation systems, including operations and management control systems, are driven by cost and financial models and are built around financial and financial objectives, and have little to do with long-term strategic objectives. Due to excessive attention to short-term financial evaluation, which left a gap between the design and implementation of the strategy, resulting in strategic development and strategic implementation of serious disjoint. In the enterprise to strengthen the strategic management to obtain a competitive advantage today, the performance evaluation system should adapt to the overall strategy requirements, and strategic business objectives closely linked to the performance evaluation into the entire strategic management process, the implementation of strategic performance evaluation as a business The Inevitable Trend of Performance Evaluation. The enterprise's strategy should be used as the starting point of performance evaluation and the starting point of management [4]. Through the performance evaluation index system so that the strategic objectives of enterprises into a phased, specific, operational and for most people to understand the objectives of the performance evaluation index system into the whole process of strategic management, truly embodied in corporate strategy The idea of managing the service.

\section{B. Combination of financial and non-financial indicators}

Financial indicators are an important aspect of evaluating corporate strategic performance, but it cannot and cannot cover all performance evaluation. The evaluation index system of financial performance emphasizes the evaluation of the impact of internal factors on the operating performance, ignoring the evaluation of the external factors. However, the evaluation of performance in addition to pay attention to the internal management level and productivity improvement, should pay full attention to external factors such as customer satisfaction, product market share, technological innovation and product innovation and other factors. In general, the financial indicators are lagging behind due to their financial statements, rather than financial indicators, such as the customer level, the staff level and the internal production and management process level and other related indicators, most can reflect the trend of enterprise development, with a certain Predictive effect, can effectively compensate for a single financial performance evaluation index system easily lead to shortcomings of corporate short-term behavior.

\section{Focus on knowledge and intellectual capital and other intangible assets evaluation}

With the arrival of the knowledge economy, the core profit source of the enterprise's survival and development has undergone substantive changes, from the physical asset-based, evolved into physical assets and financial assets, and further evolution For the financial assets and intangible assets. In some emerging enterprises, the core profit source and core competitiveness of enterprises are more and more reflected in 
some high-value intangible assets, including intangible assets within the enterprise, including the external value chain, these Intangible assets are essentially the accumulation of internal knowledge and the embodiment of intellectual capital.

\section{Focus on the overall business process evaluation}

At present, the traditional enterprise performance evaluation focuses on the evaluation of a single enterprise or a single functional department. Each department is considered to be an independent individual in an enterprise organization, with its own goals and performance evaluation criteria set. Managers focus on improving performance departments to ensure that goals are implemented and less concerned about the impact of their departmental goals on members of other departments or other supply chains. In addition, the traditional evaluation methods applicable to static products and mass production can not reflect the dynamic operation of the supply chain, and can not evaluate the business process in real time.

\section{E. Focus on innovative performance evaluation to form a sustained core competitive advantage}

A core competitiveness of enterprises is the long-term development of enterprises and business performance has been improved to ensure a strong guarantee for the success of business strategy. Enterprise innovation and core competitiveness is the relationship between each other: there is no core competitiveness of the formation and maintenance of the desire, there is no innovation power, there is no innovation and no core competitiveness of the formation. As the famous economist Robert Elli said: technology is a powerful weapon for enterprises to participate in global competition [5]. From the formation of the dominant position of the market point of view, innovation can make enterprises in the market competition to gain advantage, can enable enterprises to more quickly develop new market areas. From the enterprise development point of view, continuous innovation is conducive to the long-term development of enterprises to improve their competitiveness and reduce the uncertainty of the future business. Innovation is the key factor in the formation and maintenance of the core competitiveness of enterprises.

\section{CONCLUSION}

The evaluation of enterprise performance will conform to the requirements of modern enterprise management and integrate it into the whole strategic management process. The strategic goal will be the starting point and the starting point of management performance. The establishment of the index system will be perfected and expanded on the basis of traditional performance evaluation, forming a dynamic real-time performance evaluation index system that fully reflects the strategic management requirements of enterprises and reflects the financial and non-financial indicators of the core competitiveness and knowledge and intellectual capital is the development of enterprise performance evaluation under the information economy.

\section{REFERENCES}

[1] Ke Xiaoyan.On the difficulty of enterprise performance management and countermeasures analysis. J.Management Manager . vol. 13, pp. 81-87, 2017.

[2] Yan Zhonglu, Hong Ling, Wang Weidong.Company performance management analysis and measures.J. Modern state-owned enterprises . vol. 21, pp. 153-158, 2016.

[3] Mike Bourne, Andy Neely. Implementing Performance Measurement Systems : a Literature Review. Int. J. Business Performance Management,5(1),2003.

[4] Mohammed Salloum. Explaining the Evolution of PerformanceMeasures - A Dual Case-Study Approaches. Journal of Engineering,Project,and Production Management,3(2),2013.

[5] Searcy,C. Updating Corporate Sustainability Performance Measurement Systems. Measuring Business Excellence,15(2),2011. 